\title{
Down syndrome and maternal age in South Glamorgan
}

\author{
I D YOUNG, E MAIR WILLIAMS, AND R G NEWCOMBE
}

From the Section of Medical Genetics, University Hospital of Wales, and Department of Medical Statistics, Welsh National School of Medicine, Heath Park, Cardiff

SUMMARY Seventy cases of Down syndrome have been ascertained in South Glamorgan during the period 1968 to 1976 . This gives an overall incidence of 1 in 658 live births. Analysis of the data on the basis of single years of maternal age gives an incidence of 1 in 200 by 36 years, 1 in 100 by 40 years, and 1 in 50 by 44 years. All incidence figures are for live births at age of delivery.

The advent of the possibility of antenatal diagnosis for chromosomal disorders has made it essential that accurate incidence figures are available for genetic counselling. It is well known that advanced maternal age is associated with an increased incidence of Down syndrome. However, many centres only have recourse to incidence figures based on quinquennial maternal age groupings, so that a woman of 39 years will be given the same risk as one of 35 years.

In this study we have attempted to derive age specific incidences for single year intervals of maternal age, based on analysis of the incidence of Down syndrome in South Glamorgan from 1968 to 1976 inclusive.

\section{Methods}

Two sources of ascertainment have been used. The first, the Cardiff Birth Survey, is an ongoing long term study in which every child born to women resident within defined geographical boundaries has a proforma completed and registered within one month of birth. The catchment area consists of Cardiff and surrounding rural districts.

The second ascertainment source comprises the records of the departments of cytogenetics and paediatric pathology at the Regional Child Health Laboratories in Cardiff.

Where possible the diagnosis has been confirmed by consultation of cytogenetic and hospital records.

\section{Results}

A total of 70 cases of Down syndrome was ascertained, 57 from the Cardiff Birth Survey and an Received for publication 23 January 1980 additional 13 from laboratory records. This figure of 13 includes four cases diagnosed after amniocentesis and subsequently terminated. Cytogenetic confirmation was obtained in 64 cases. Trisomy 21 was present in 61 and the other three showed a translocation.

In the four cases where prenatal diagnosis was made the indications for amniocentesis were as follows (with maternal age in years at expected date of delivery in brackets): family history of neural tube malformation 1 (23); maternal anxiety 1 (34); and maternal age $2(42,44)$.

The number of total live births during the study period was 46048 giving an incidence of Down syndrome of 1 in 658 live births. This assumes that those cases terminated after prenatal diagnosis would have otherwise survived.

Because maternal age for the general population is recorded only in 5-year intervals in the birth survey, we have had to resort to the following method to derive age specific incidences based on single year intervals of maternal age. Table 1 compares the South Glamorgan figures with those obtained in a Swedish survey where total births were recorded in single year intervals. ${ }^{1}$ Among the total births to women over 25 years, the quinquennial proportions (columns 4 and 7 in table 1) are almost identical $\left(\chi^{2}=2 \cdot 788, \mathrm{df}=4, \mathrm{p} \bumpeq 0 \cdot 6\right)$, as are the ratios in column 8 . Thus since the gross structures are similar in each study, we can assume similar fine structures also and thus allocate the South Glamorgan deliveries in each quinquennium over 25 years to individual years of age. The resulting unsmoothed rates are shown in column 4 of table 2 .

These unsmoothed rates have been smoothed by fitting a simple model in which the risk increases 
TABLE 1 Distribution of maternal age in Sweden and South Glamorgan

\begin{tabular}{|c|c|c|c|c|c|c|c|}
\hline \multirow{2}{*}{$\begin{array}{l}\text { Maternal age } \\
\text { in years at birth }\end{array}$} & \multicolumn{3}{|c|}{ Sweden 1968-1970 } & \multicolumn{3}{|c|}{ South Glamorgan 1968-1976 } & \multirow{2}{*}{$\frac{(3)}{(6)}$} \\
\hline & Total live births & $\begin{array}{l}\text { As percentage of } \\
\text { total }\end{array}$ & $\begin{array}{l}\text { As percentage of } \\
\text { those aged 25-50 }\end{array}$ & Total live births & $\begin{array}{l}\text { As percentage of } \\
\text { total }\end{array}$ & $\begin{array}{l}\text { As percentage of } \\
\text { those aged } 25-50\end{array}$ & \\
\hline (I) & (2) & (3) & (4) & (5) & $(6)$ & (7) & (8) \\
\hline $45-50$ & 306 & 0.09 & 0.17 & 46 & $0 \cdot 10$ & 0.19 & 0.926 \\
\hline $40-44$ & 4880 & $1 \cdot 48$ & $2 \cdot 67$ & 597 & $1 \cdot 30$ & $2 \cdot 52$ & $1 \cdot 138$ \\
\hline $35-39$ & 19522 & $5 \cdot 90$ & 10.67 & 2549 & $5 \cdot 54$ & $10 \cdot 77$ & 1.065 \\
\hline $30-34$ & 49487 & $14 \cdot 96$ & 27.05 & 6416 & $13 \cdot 93$ & $27 \cdot 11$ & 1.073 \\
\hline $25-29$ & 108746 & $32 \cdot 87$ & 59.44 & 14061 & $30 \cdot 54$ & $59 \cdot 41$ & $1 \cdot 076$ \\
\hline $25-50$ & 182941 & $55 \cdot 30$ & $100 \cdot 00$ & 23669 & $51 \cdot 41$ & $100 \cdot 00$ & $1 \cdot 076$ \\
\hline $\begin{array}{l}20-24 \\
15-19\end{array}$ & $\begin{array}{r}117593 \\
30272\end{array}$ & $\begin{array}{r}35 \cdot 55 \\
9 \cdot 15\end{array}$ & & $\begin{array}{r}15960 \\
6419\end{array}$ & $\begin{array}{l}34 \cdot 66 \\
13 \cdot 94\end{array}$ & & $\begin{array}{l}1.026 \\
0.656\end{array}$ \\
\hline $15-50$ & 330806 & $100 \cdot 00$ & & 46048 & $100 \cdot 01$ & & \\
\hline
\end{tabular}

TABLE 2 Fitted yearly values for total deliveries and Down syndrome incidences, South Glamorgan 1968-1976

\begin{tabular}{|c|c|c|c|c|c|c|c|c|}
\hline \multirow{3}{*}{$\begin{array}{l}\text { Age at birth } \\
\text { in years }\end{array}$} & \multicolumn{2}{|c|}{ South Glamorgan } & \multirow{2}{*}{\multicolumn{2}{|c|}{$\begin{array}{l}\text { Unsmoothed rates per } 1000 \\
\text { live births }\end{array}$}} & \multicolumn{4}{|c|}{ Smoothed South Glamorgan rates per 1000 live births } \\
\hline & \multirow{2}{*}{$\begin{array}{l}\text { Down } \\
\text { births }\end{array}$} & \multirow{2}{*}{$\begin{array}{l}\text { Total live } \\
\text { births }\end{array}$} & & & \multirow{2}{*}{ (a) } & \multirow{2}{*}{ (b) } & \multirow{2}{*}{$(c)$} & \multirow{2}{*}{$(d)$} \\
\hline & & & $\begin{array}{l}\text { South } \\
\text { Glamorgan }\end{array}$ & Sweden & & & & \\
\hline $15-19$ & 1 & 6419 & 0.156 & 0.595 & & & & \\
\hline $20-24$ & 11 & 15960 & 0.689 & 0.740 & & & & \\
\hline 25 & 3 & 3559 & 0.843 & 0.799 & \multirow{5}{*}{\multicolumn{4}{|c|}{$\begin{array}{l}\text { Swedish data have been used to derive the values in columns } \\
\text { (a), (b), and (c). The Registrar General's Statistical Values for } \\
1972 \text { for England and Wales have been used to derive } \\
\text { column (d). }\end{array}$}} \\
\hline 26 & 3 & 3235 & 0.927 & 0.919 & & & & \\
\hline 27 & 4 & 2805 & 1.426 & 0.738 & & & & \\
\hline 28 & 1 & 2406 & 0.415 & 0.967 & & & & \\
\hline 29 & 1 & 2054 & 0.487 & $1 \cdot 070$ & & & & \\
\hline 30 & 5 & 1794 & $2 \cdot 787$ & 0.795 & 2.078 & $2 \cdot 280$ & $2 \cdot 107$ & 2.098 \\
\hline 31 & 3 & 1496 & 2.005 & $1 \cdot 820$ & 2.468 & 2.664 & 2.496 & 2.488 \\
\hline 32 & 7 & 1242 & 5.636 & $1 \cdot 044$ & 2.932 & $3 \cdot 113$ & 2.958 & 2.951 \\
\hline 33 & 2 & 1019 & 1.963 & 2.035 & $3 \cdot 438$ & 3.638 & $3 \cdot 506$ & $3 \cdot 500$ \\
\hline 34 & 2 & 865 & $2 \cdot 312$ & 2.098 & $4 \cdot 137$ & $4 \cdot 252$ & $4 \cdot 154$ & $4 \cdot 151$ \\
\hline 35 & 2 & 707 & $2 \cdot 829$ & 2.032 & 4.914 & 4.969 & 4.923 & $4 \cdot 923$ \\
\hline 38 & 3 & 409 & $7 \cdot 335$ & $5 \cdot 113$ & $8 \cdot 235$ & 7.930 & $8 \cdot 192$ & $8 \cdot 212$ \\
\hline 39 & 5 & 315 & $15 \cdot 873$ & 6.625 & $9 \cdot 781$ & $9 \cdot 268$ & $9 \cdot 707$ & 9.739 \\
\hline 40 & 0 & 221 & 0 & $12 \cdot 188$ & $11 \cdot 618$ & $10 \cdot 831$ & $11 \cdot 503$ & $11 \cdot 550$ \\
\hline 41 & 2 & 164 & $12 \cdot 195$ & 12.658 & 13.800 & $12 \cdot 657$ & $13 \cdot 632$ & 13.698 \\
\hline 42 & 3 & 103 & $29 \cdot 126$ & $17 \cdot 751$ & $16 \cdot 392$ & $14 \cdot 792$ & $16 \cdot 154$ & $16 \cdot 246$ \\
\hline 43 & 2 & 65 & $30 \cdot 769$ & $11 \cdot 385$ & $19 \cdot 471$ & $17 \cdot 286$ & $19 \cdot 142$ & $19 \cdot 267$ \\
\hline 44 & 1 & 44 & $22 \cdot 727$ & $36 \cdot 111$ & $23 \cdot 127$ & $20 \cdot 201$ & $22 \cdot 684$ & $22 \cdot 851$ \\
\hline $45-50$ & 2 & 46 & $43 \cdot 478$ & 62.092 & & & & \\
\hline
\end{tabular}

exponentially with age. There are several different ways of fitting such a model. A weighted least squares regression leads to estimated rates which give only 39.965 Down syndrome births to South Glamorgan women aged 30 to 44 during the study period, $\mathbf{9} \cdot 2 \%$ lower than the 44 observed. The rates in column (a) of table 2 represent values fitted in this way grossed up by a constant factor to give a total of $\mathbf{4 4}$ Down syndrome births.

Such a process seems somewhat artificial and an unweighted least squares fit was performed as follows. Let $\alpha$ denote the ratio by which the risk increases for a one year increase in age. Let $t=30$, $31, \ldots 44$ denote the ages studied and let $D_{t}$ and $N_{t}$ be the Down syndrome and total births to mothers aged $\mathrm{t}$ at last birthday. Let $\mathrm{K}$ denote the risk at the baseline age 30 . Then in order to satisfy the constraint that the model should give a total of $\Sigma D_{t}=$ 44 Down syndrome births, we require $K=44 / \Sigma \alpha^{t^{-30}}$ $N_{t}$. A value of $\alpha$ is chosen, $K$ is deduced, and the unweighted residual sum of squares $S S=\Sigma\left(D_{t}\right.$ $\left.\mathrm{K} \alpha^{\mathrm{t}^{-30}} \mathrm{~N}_{\mathrm{t}}\right)^{2}$ is calculated. An iterative procedure is adopted to minimise SS. The resulting fitted rates $\mathrm{K} \alpha^{\mathrm{t}-30}$ are given in column (b) of table 2 , and lead to a value of SS of 33.28 which is better than the 33.68 obtained in process (a).

However, the discrepancy between observed and fitted rates is now somewhat correlated with age. Method (b) yields a regression coefficient of residual against age of +0.0326 which is opposite to and more serious than -0.0056 found under method (a). It is clear that there exists a solution shown under 
column (c) that is strictly better than (a), with regression coefficient zero and a lower value of $\mathrm{SS}=33 \cdot 57$.

The three fitted models agree closely; they never differ by as much as the effect of one year of age, largely because they are constrained to concur at around the weighted mean age 36 and thus differ only in slope. The risk passes 1 in 200 as a woman reaches age 36 and passes 1 in 100 as she reaches 40 .

The South Glamorgan data indicate a rate of increase of incidence with age of 16.9 to $18.8 \%$ per year, slower than the $31 \%$ fitted to the Swedish data.

Similar steps have been carried out using British rather than Swedish data to split the numbers of births in the three quinquennia of maternal age into single years. The closeness of fit between the South Glamorgan quinquennial figures and those obtained from the Registrar General's figures for 1972 was acceptable $\left(\chi^{2}=6.943, p=0.03\right)$ and the calculations were repeated accordingly. The resulting smoothed rates, corresponding to those derived using Swedish data and shown in column (c), form column (d) of table 2 and are virtually identical to those in column (c). They have the further advantage of a slightly lower residual SS equal to $33 \cdot 25$.

These smoothed rates are shown graphically in the figure.

\section{Discussion}

This study yields an incidence for Down syndrome of 1 in 658 live births. It is likely that this figure represents the true incidence since any cases missed by

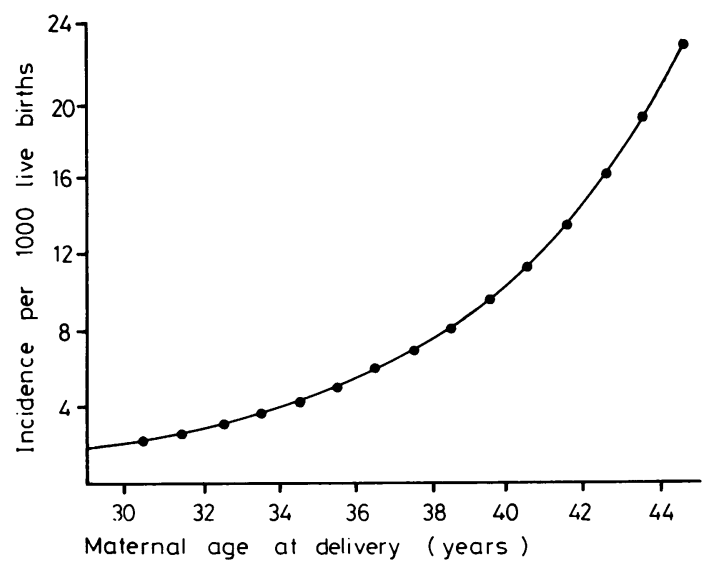

FIGURE Smoothed South Glamorgan incidence rates per 1000 live births' the Cardiff Birth Survey will have been ascertained through the Child Health Laboratory records. Other British studies have found similar values of 1 in 660 in London, ${ }^{2} 1$ in 613 in Northampton, ${ }^{3} 1$ in 672 in Newcastle, ${ }^{4}$ and 1 in 617 in Birmingham. ${ }^{5}$

The provision of precise risk figures to mothers over 35 years is difficult because most reports quote specific incidence values based on 5-year intervals of maternal age. In this report we have attempted to provide live birth incidence figures based on single years of maternal age. That this is important is illustrated by the doubling of risk from 35 to 39 years. Clearly a quinquennial 'average' risk is not appropriate.

We have compared the gross structure of age at delivery in South Glamorgan women with that in England and Wales as a whole and in Sweden. Since these gross structures are similar, this not only allows us to derive single year incidence values, which can then be smoothed, but also prompts us to suggest that these incidence figures can reasonably be used for counselling purposes in other United Kingdom centres.

An additional factor which complicates genetic counselling is the persistent discrepancy described between amniocentesis and live birth incidences for Down syndrome in mothers over 35 years, as illustrated in table 3. Possible explanations for this difference include fetal wastage after 16 weeks, biased high risk referral groups, preferential reporting from centres finding high incidences, incomplete live birth ascertainment, skewed maternal age distribution in amniocentesis samples, an increased incidence in the United Kingdom (many of the amniocentesis figures originate in Britain), and an increasing incidence in older mothers which would be reflected in the more contemporary amniocentesis figures. ${ }^{1314}$ It is likely that all of these factors have contributed. In table 4, the South Glamorgan and

TABLE 3 Fractional incidence of Down syndrome (per 1000 cases)

\begin{tabular}{llc}
\hline & \multicolumn{2}{c}{ Maternal age at delivery in years } \\
\cline { 2 - 3 } & $35-39$ & $40-44$ \\
\hline Livebirth studies & & \\
London 19512 & $3 \cdot 52$ & $14 \cdot 18$ \\
Australia 19626 & $3 \cdot 50$ & $9 \cdot 93$ \\
Sweden 19747 & $3 \cdot 74$ & $14 \cdot 96$ \\
Copenhagen 19768 & $3 \cdot 04$ & $14 \cdot 61$ \\
New York State 19769 & & \\
$\quad$ (estimated) & $4 \cdot 03$ & $12 \cdot 68$ \\
$\quad$ Amniocentesis studies & & \\
Glasgow 197610 & $8 \cdot 0$ & $46 \cdot 0$ \\
London 197811 & $5 \cdot 6$ & $105 \cdot 3$ \\
Europe 197912 & $8 \cdot 4$ & $23 \cdot 1$ \\
\hline
\end{tabular}

All dates relate to publication, not to the period of study. 
TABLE 4 Incidence of Down syndrome in cases per 1000

\begin{tabular}{|c|c|c|c|}
\hline $\begin{array}{l}\text { Maternal age } \\
\text { at delivery }\end{array}$ & $\begin{array}{l}\text { South } \\
\text { Glamorgan } \\
\text { live born } \\
\text { (smoothed) }\end{array}$ & $\begin{array}{l}\text { Sweden live } \\
\text { born } 1 \\
\text { (unsmoothed) }\end{array}$ & $\begin{array}{l}\text { Europe } \\
\text { amniocentesis }^{12}\end{array}$ \\
\hline $\begin{array}{l}35 \\
36 \\
37 \\
38 \\
39 \\
40 \\
41 \\
42 \\
43 \\
44\end{array}$ & $\begin{array}{r}4 \cdot 91 \\
5 \cdot 84 \\
6 \cdot 93 \\
8 \cdot 24 \\
9 \cdot 78 \\
11 \cdot 62 \\
13 \cdot 80 \\
16 \cdot 39 \\
19 \cdot 47 \\
23 \cdot 13\end{array}$ & $\begin{array}{r}2 \cdot 03 \\
2 \cdot 58 \\
4 \cdot 60 \\
5 \cdot 11 \\
6 \cdot 63 \\
12 \cdot 19 \\
12 \cdot 66 \\
17 \cdot 75 \\
11 \cdot 39 \\
36 \cdot 11\end{array}$ & $\begin{array}{r}4 \cdot 5 \\
4 \cdot 9 \\
7 \cdot 7 \\
9 \cdot 1 \\
13 \cdot 2 \\
12 \cdot 0 \\
23 \cdot 4 \\
33 \cdot 3 \\
17 \cdot 8 \\
55 \cdot 9\end{array}$ \\
\hline
\end{tabular}

Swedish live birth figures for mothers over 35 years are presented with the amniocentesis values based on pooled data from 32 European centres. ${ }^{12}$ Comparison of these figures indicates that the true amniocentesis and live birth incidences may not be as widely disparate as previously indicated.

An alarming feature of the South Glamorgan incidence figures is that they are higher than other reported live birth values for mothers over 30 years, although lower in the youngest age groups. Recent reports from Copenhagen, ${ }^{8}$ Edinburgh, ${ }^{15}$ and Winnipeg ${ }^{16}$ indicate that the age specific incidence at birth of Down syndrome is rising in mothers over 35 years, although a large comprehensive Australian study does not support this. ${ }^{17}$ Taken in conjunction with the South Glamorgan figures, these reports of a rising incidence could be interpreted as evidence that women are being exposed at an increasingly early age to as yet unknown environmental agents whose cumulative effect would be to predispose to nondisjunction.

An alternative explanation for this reported increasing incidence in older mothers is that the social and biological characteristics have changed in those women who now become pregnant at advanced age. Thus the apparent increase in incidence may be spurious and simply reflect a changing pattern in the social structure of those women over 35 who become pregnant. Interrelated factors such as improved prenatal care and better nutrition resulting in reduced fetal loss of Down syndrome conceptions may also be important.

Whatever the true cause of these reported high incidences in the older mother, they carry important implications for the planning and provision of prenatal services and illustrate the need for better understanding of those factors which induce nondisjunction.
We are indebted to Mrs Marjorie Dauncey for providing data from the Cardiff Birth Survey, and to Professor K M Laurence and Mr P Gregory of the Child Health Laboratories in Cardiff for allowing us access to the Laboratory records. We also wish to thank Dr P S Harper for advice and encouragement.

This paper was presented at the Clinical Genetics Society in November, 1979.

\section{References}

1 Hook EB, Lindsjö A. Down syndrome in live births by single year maternal age interval in a Swedish study: comparison with results from a New York State study. Am J Hum Genet 1978;30:19-27.

2 Carter C, MacCarthy D. Incidence of mongolism and its diagnosis in the newborn. Br J Soc Med 1951;5:83-90.

3 Pleydell MJ. Mongolism and other congenital abnormalities. An epidemiological study in Northamptonshire. Lancet 1957; : :1314-9.

4 Buchan AR. A study of mongolism in Newcastle upon Tyne 1948-1959. The Medical Officer 1962;107:51-4.

5 Leck I. Incidence and epidemicity of Down's syndrome. Lancet 1966 ;ii:457-60.

6 Collmann RD, Stoller A. A survey of mongoloid births in Victoria, Australia, 1942-57. Am J Public Health 1962; 52:813-29.

7 Lindsjö A. Down's syndrome in Sweden. An epidemiological study of a three-year material. Acta Paediatr Scand 1974;63:571-6.

8 Mikkelsen M, Fischer G, Stene J, Stene E, Petersen E. Incidence study of Down's syndrome in Copenhagen, 1960-1971: with chromosome investigation. Ann Hum Genet 1976;40:177-82.

9 Hook EB. Estimates of maternal age-specific risks of a Down-syndrome birth in women aged 34-41. Lancet 1976;ii: 33-4.

10 Ferguson-Smith MA. Prospective data on risk of Down syndrome in relation to maternal age. Lancet $1976 ;$ ii :252.

11 Meredith R, Taylor AI, Ansl FM. High risk of Down's syndrome at advanced maternal age. Lancet 1978;i:564-5.

12 Ferguson-Smith MA. Advanced maternal age. In: Proceedings of the Third European Conference on Prenatal Diagnosis of Genetic Disorders. Stuttgart: Ferdinand Enke, 1979:1-14.

13 Polani PE, Alberman E, Berry AC, Blunt S, Singer JD. Chromosome abnormalities and maternal age. Lancet 1976;ii:516-7.

14 Editorial. Maternal age and Down's syndrome. Lancet 1978 ;ii :24-5.

15 Holloway S, Emery AEH. Factors affecting the incidence of Down syndrome in Scotland. J Biosoc Sci 1977;9: 453-65.

16 Evans JA, Hunter AGW, Hamerton JL. Down syndrome and recent demographic trends in Manitoba. $J$ Med Genet 1978;15:43-7.

17 Sutherland GR, Clisby SR, Bloor G, Carter RF. Down's syndrome in South Australia. Med J Aust 1979;2:58-61.

Requests for reprints to Dr I D Young, Section of Medical Genetics, University Hospital of Wales, Heath Park, Cardiff CF4 4XW. 